\title{
Burnout and depression among psychiatry residents during COVID-19 pandemic
}

\author{
Abdulmajeed A. Alkhamees ${ }^{1 *}$ (D) Hatem Assiri ${ }^{2}$, Hatim Yousef Alharbi ${ }^{3}$, Abdullah Nasser $^{3}$ and \\ Mohammad A. Alkhamees ${ }^{4}$
}

\begin{abstract}
Very few studies have been concerned with assessing the prevalence of burnout and depressive symptoms, especially during an infectious outbreak on non-frontline health care workers, such as a psychiatrist. In such instances, the role of psychiatrists and other mental health providers as a source of psychological support to the public and frontline workers is indispensable and valuable. This study aims to assess the prevalence of burnout and depressive symptoms, and their correlation, during the COVID-19 pandemic among psychiatry residents in Saudi Arabia. A total of 121 out of 150 psychiatry residents in Saudi Arabia completed the Maslach Burnout Inventory and Patient's Health Questionnaire for the assessment of burnout and depressive symptoms. Burnout symptoms were found in $27.3 \%$, and another $27.3 \%$ reported having depression symptoms. In addition, $16.5 \%$ reported having both burnout and depressive symptoms, with a significant relationship between them. Participants in the first 2 years of training and having a history of receiving mental health treatment in the past 2 years were at higher risk. The need is urgent to increase investment in mental health services and to construct a plan to reduce this risk of burnout and depression among psychiatrists by developing preventative strategies to prevent burnout and promote wellness is more important than ever.
\end{abstract}

Keywords: COVID 19, Burnout, Depression, Psychiatry, Resident, Pandemic, Saudi Arabia

\section{Introduction}

The coronavirus disease of 2019 (COVID-19) pandemic has left health-care systems around the globe faced with challenging difficulties combating the pandemic and its impact. Health care providers have responded tirelessly to deal with these difficult times. The pandemic has left health care providers facing increased work demands and related stress, which has worsened already-existing burnout among health care providers [1].

After the first case was discovered in Saudi Arabia, the government response was immediate and swift; they launched a social media campaign encouraging people to stay at home and to practice social distancing, and to

*Correspondence: abdulmajeed.kms@gmail.com; A.alkhamees@qu.edu.sa ${ }^{1}$ Department of Medicine, Unaizah College of Medicine and Medical Sciences, Qassim University, Buraydah, Al Qassim, Saudi Arabia

Full list of author information is available at the end of the article follow the instruction put out by the Ministry of Health [2]. On March 23, a lockdown was imposed on Mecca, Medina, and Riyadh with travel restrictions all over the country, and within the next 10 days, the curfew was extended to $24 \mathrm{~h}$ [3].

The notion of burnout was introduced in the scientific literature by Herbert J. Freudenberger's work in 1974 [4]. Since then, this concept has evolved, and various definitions have emerged. Maslach and Jackson promoted the most commonly used definition [5]. They defined burnout as a psychological syndrome affecting mainly professionals working with other people in difficult circumstances, such as health care providers. Burnout is characterized by emotional exhaustion (tiredness and a feeling of being unable to provide more to others), depersonalization (impersonal feelings toward their patients, dealing with them as objects), and deficiency in the feeling of personal achievements [6]. original author(s) and the source, provide a link to the Creative Commons licence, and indicate if changes were made. The images or other third party material in this article are included in the article's Creative Commons licence, unless indicated otherwise in a credit line to the material. If material is not included in the article's Creative Commons licence and your intended use is not permitted by statutory regulation or exceeds the permitted use, you will need to obtain permission directly from the copyright holder. To view a copy of this licence, visit http://creativecommons.org/licenses/by/4.0/. The Creative Commons Public Domain Dedication waiver (http://creativeco mmons.org/publicdomain/zero/1.0/) applies to the data made available in this article, unless otherwise stated in a credit line to the data. 
The idea of overlap between burnout and depression has been supported by many published papers, including the results of research conducted among health care workers, which proposed that burnout is a manifestation of the depressive syndrome [7], 8 .

Furthermore, Ahola et al. concluded that using a person-centered approach, depressive symptoms and burnout appear to form a single entity together or to develop in a parallel manner. These findings accentuate the conceptual similarity of burnout and depressive symptoms in a work context [9].

Numerous studies have explored the effect of an infectious disease outbreak on health care workers' mental health. Recently, Ricci-Cabello et al. conducted a rapid systematic review that included 56 studies. They assessed a wide range of disturbing psychological reactions for their impact on the mental health of workers providing health care during or after health emergencies caused by viral epidemic outbreaks. Anxiety (45\%) was the highest pooled prevalence, followed by depression (38\%), acute stress disorder (31\%), and post-traumatic stress disorder (19\%), while the prevalence of burnout was $29 \%$ (in 1,168 participants), as reported by three studies [10].

In 2016, Jovanovic conducted an online survey of burnout syndrome among psychiatric trainees in 22 countries and found that about $36.7 \%$ had severe burnout [11].

In addition to the stressors of being a health-care provider, being a psychiatry trainee added more and different burdens, such as perceived stigma related to their chosen specialty, the ongoing demands of establishing therapeutic relationships with their patients, personal threats from violent patients, and patient suicide [12].

Tackling the mental health of health care workers during this pandemic is essential and will strengthen the capacity of health-care systems [13]. Unfortunately, few studies have assessed the prevalence of burnout during pandemic globally and locally. In addition, there is a lack of knowledge about the impact of an infectious disease outbreak on non-frontline health care workers such as psychiatrists. The role of psychiatrists and other mental health providers in such an instance as a source of psychological support and reassurance to the public and frontline workers is indispensable and valuable.

Furthermore, many authors tried to assess common sociodemographic factors that correlate with experiencing burnout and depressive symptoms among psychiatry residents. Tracking and identifying these factors are of great importance, as it allows us from a preventive perspective to identify and provide the necessary interventions early and for those who are more vulnerable than the other to the occurrence of burnout and depression. In their systematic review, Min Kai Chan et al. [14], in their systematic review found that having children being in early years of training (junior level) associated with reporting more burnout. Regarding depression being female and junior level of training were related to increase risk of developing depressive symptoms compared to counterpart [15].

To the best of our knowledge, there is a lack of studies that try to explore the relationship between these sociodemographic characteristics and the rates of burnout and depression on mental health trainees, especially during the period of pandemics.

This study aims to assess the prevalence of burnout and depression, and their correlation, during the COVID-19 pandemic among psychiatry residents in Saudi Arabia. A secondary aim is to assess sociodemographic characteristics and their correlation with burnout and depression among psychiatry residents in Saudi Arabia.

\section{Materials and methods Study design and setting}

This study followed a cross-sectional design to assess psychiatry resident burnout and depression symptoms during the COVID-19 pandemic after the lockdown was imposed in Saudi Arabia. There are more than 150 psychiatry residents in Saudi Arabia divided into three training locations, the program consists of four training years divided into a junior level (R1-R2) and a senior level (R2-R3) with rotation in inpatient psychiatry unit and outpatient clinic and rotation in consultation-liaison psychiatry and other different rotations, and residents are required to pass a yearly promotional exam to pass to the next year.

All Saudi psychiatry residents located in Saudi Arabia were included. We used an online questionnaire distributed to all residents using WhatsApp groups. Physical distribution was not feasible due to the lockdown in the Kingdom at that time.

\section{Study procedure}

The survey was distributed after the curfew was imposed in Saudi Arabia, and the practice of social distancing was encouraged. The Saudi Ministry of Health enforced a strict protocol to reduce unnecessary hospital visits. We followed an online data collection technique. The survey was done online using a common platform, google survey (Google LLC, Mountain View, California, USA). The study protocol was approved by the Institutional Review Board of Qassim University (No.19-10-02). All participants were informed about the study purposes and provided informed consent. Data were kept confidential and were not disclosed unless for study purposes. Data were collected over a 1-month period (March 15 to April 23, 2020). 


\section{Variables and instruments}

The survey included sociodemographic data-participants' gender, age, marital status, parental status-as well as the location and level of the residency program. Participants also completed the Maslach Burnout Inventory (Human Services Survey; MBI-HSS) and the Patient's Health Questionnaire (PHQ-9) for the assessment of burnout and depression.

The MBI-HSS is an assessment test developed by Maslach and Jackson in 1981 to measure personally perceived burnout [16, 17]. This scale has been used extensively to measure burnout in medical team members. The scale includes three domains: 1) emotional exhaustion (EE), 2) depersonalization (DP), and 3) personal accomplishment (PA). Each item measures a specific domain based on a 7-point scale, varying from "never" to "every day." Scores for EE, DP, and PA range from 0 to 54, 0 to 30 , and 0 to 48 , respectively. [18]. High scores on the EE $(\geq 27)$ and DP $(\geq 13)$ subscales or a low score on the PA subscale $(\leq 31)$ were considered highly suggestive of burnout symptoms [18]. Respondents with scores $\geq 27$ on the EE subscale and/or $\geq 13$ on the DP subscale were considered to be suffering from burnout $[16,17]$.

The PHQ-9 is a self-administered diagnostic instrument used for identifying depressive symptoms and monitoring their severity. The PHQ-9 has been validated in several studies from different populations [19]. Total scores of $10-14$ points, $15-19$ points, and $20-27$ points indicate, respectively, moderate, moderately severe, and severe levels of depressive symptoms. Participant with a score of 10 or more on the PHQ- 9 was considered as having depressive symptoms. [20], 21.

Both the MBI and PHQ-9 were found to have high internal consistency, with the 22-item MBI having a Cronbach's alpha of 0.80 and the 9-item PHQ-9 having a Cronbach's alpha of 0.89 . When tested for their reliability, each of the subscales of the MBI performed well, with the Cronbach's alpha of the EE, DP, and PA subscales being $0.91,0.81$, and 0.72 , respectively.

\section{Statistical analysis}

In line with the data collection approach earlier described, data was collected from respondents and responses entered into a Microsoft Excel spreadsheet and subsequently transferred to IBM SPSS Statistics for Windows, version 22.0 (IBM Corp., Armonk, N.Y., USA) for analysis. Descriptive analysis was carried out and the results presented as percentages and frequencies for categorical variables; and means and standard deviation for continuous variables. Univariate test of associations was carried out to determine associations between categorical variables and outcomes such as burnout and depression.
Logistic regression was carried out to evaluate independent associations between the outcomes (burnout/ depression) and factors such as sociodemographic and educational characteristics. The results of the univariate tests and logistic regressions were presented using crude odds ratio (COR) and adjusted odds ratio (AOR) with 95\% confidence interval (CI). All tests were carried out at a significance level set at $\mathrm{p}<0.05$. Adjusted ORs for the relationship between depression and burnout were based on adjustment for components of the burnout scale. Similarly, adjusted ORs for the relationship between sociodemographic/educational factors and burnout/depression were based on adjustment for potential confounders such as "age", "sex", "marital status", "raising children", "current level", and "got mental help".

\section{Results}

\section{Sociodemographic and educational characteristics}

A total of 121 out of 150 psychiatry residents responded (response rate $80.6 \%$ ), as presented in Table 1. The majority of them were within the $24-28$-year age range (67.8\%),

Table 1 Sociodemographic and educational characteristics of the study population $(n=121)$

\begin{tabular}{lcc}
\hline Variables & Frequency & Percent \\
\hline Age & & \\
24-28 years & 82 & 67.8 \\
29-33 years & 38 & 31.4 \\
34-38 years & 1 & 0.8 \\
Gender & & \\
Male & 70 & 57.9 \\
Female & 51 & 42.1 \\
Marital status & & \\
Single & 63 & 52.1 \\
Married & 54 & 44.6 \\
Divorced & 4 & 3.3 \\
Raising children & & \\
No & 92 & 76.0 \\
Yes & 29 & 24.0 \\
Location of psychiatry residency program & & \\
Riyadh & 51 & 42.1 \\
Dammam & 31 & 25.6 \\
Jeddah & 39 & 32.2 \\
Current level in residency & & \\
R1 & 27.3 \\
R2 & 33 & 27.3 \\
R3 & 32.3 \\
R4 & 29 & 77.7 \\
Received mental help in the last 2 years & 33 & \\
Yes & 27 & 27.3 \\
\hline & & \\
\hline
\end{tabular}


closely followed by those between the ages of 29 and 33 years (31.4\%). There were more males $(57.9 \%)$ than females. With regard to their marital statuses, $52.1 \%$ of them were single, while another $44.6 \%$ were married at the time of the study. Only about a quarter of the study population had children they were currently raising $(24.0 \%)$ at the time data was collected. For their psychiatry residency programs, most of the respondents were having theirs in Riyadh (42.1\%), followed by those in Jeddah (32.2\%) and Dammam (25.6\%). The split across the four levels of psychiatry residency (R1-R4) is similar to the largest groups being those in R2 (27.3\%) and R3 (26.4\%). About a quarter of the study population (22.3\%) had received mental health help for different reasons within the previous 2 years.

\section{Prevalence of burnout and depressive symptoms among the study population}

The summary of findings on the prevalence of burnout and depressive symptoms is presented in Table 2. Overall, $26.4 \%$ of the entire population had high emotional exhaustion, $10.7 \%$ met the criteria for high depersonalization, and $24.0 \%$ demonstrated low personal accomplishment. Combining these findings, about a quarter of the population had either high emotional exhaustion and/or high depersonalization and were determined to be suffering from burnout (27.3\%). Going further to look at depressive symptoms, $27.3 \%$ of the population were determined to suffer from depressive symptoms, with a split into those who had moderate depressive symptoms in the majority (60.6\%), followed by those with

Table 2 Prevalence of burnout and depressive symptoms among the study population $(n=121)$

\begin{tabular}{|c|c|c|}
\hline Variables & Frequency & Percent (\%) \\
\hline \multicolumn{3}{|l|}{ Burnout syndrome $^{a}(n=121)$} \\
\hline Yes & 33 & 27.3 \\
\hline No & 88 & 72.7 \\
\hline \multicolumn{3}{|l|}{ Burnout subscales $(n=121)$} \\
\hline High emotional exhaustion & 32 & 26.4 \\
\hline High depersonalization & 13 & 10.7 \\
\hline Low personal accomplishment & 29 & 24.0 \\
\hline \multicolumn{3}{|l|}{ Depressive symptoms $(n=121)$} \\
\hline Yes & 33 & 27.3 \\
\hline No & 88 & 72.7 \\
\hline \multicolumn{3}{|l|}{ Severity of depressive symptoms $(n=33)$} \\
\hline Moderate depressive symptoms & 20 & 60.6 \\
\hline Moderately severe depressive symptoms & 7 & 21.2 \\
\hline Severe depressive symptoms & 6 & 18.2 \\
\hline
\end{tabular}

a Determined based on respondents having a high score on the emotional exhaustion and/or depersonalization subscales (see "Methods") moderately severe depressive symptoms (21.2\%), and severe depressive symptoms (18.2\%).

\section{Relationship between burnout and depressive symptoms}

There was a relationship between burnout and depressive symptoms, as illustrated in Fig. 1. Respondents who suffered from burnout were significantly 8.88 times more likely to have depressive symptoms (95\% CI 3.56-22.13, $\mathrm{p}<0.001)$. The relationship between respondents' performance on the burnout scales and depressive symptoms are summarized in Table 3. High scores on all three subscales (emotional exhaustion, depersonalization, and personal accomplishment) were significantly predictive of depressive symptoms $(\mathrm{p}<0.05)$.

\section{Relationships between sociodemographic factors and burnout syndrome}

Several sociodemographic and educational factors were found to have an impact on whether or not the respondents experienced burnout (Table 4). Of all the factors tested, which include age, sex, marital status, raising children, and current level in residency, none had a statistically significant impact on the prevalence of burnout. Even though not found to be statistically significant, respondents who were currently alone based on their marital status (single or divorced) were more likely than their married counterparts to experience burnout (COR: $1.34,95 \%$ CI 0.59-3.03). Similarly, those who were in residency years 1 and 2 were more likely than those in years 3 and 4 to have burnout (COR: 1.56, 95\% CI 0.69-3.49; AOR: 1.52 , 95\% CI 0.60-3.81). Respondents between the ages of 24 and 28 years, males, and currently raising children were less likely to have burnout $(\mathrm{p}>0.05)$. Beyond these factors, however, respondents who had received mental health help in the preceding 2 years before the study were 6.59 times significantly more likely on the Crude odds ratio scale (95\% CI 2.60-16.70) to experience burnout than those who have not $(\mathrm{p}<0.05)$.

\section{Relationships between sociodemographic factors and depressive symptoms}

With regards to factors influencing depressive symptoms, age, sex, and current level in residency were factors found to have a statistically significant influence on whether or not the respondents were depressed (Table 5). Respondents who were between the ages of 24 and 28 were less likely than those 29 years or more to have depressive symptoms (COR: 0.65 , 95\% CI 0.28 1.49; AOR: 0.29, 95\% CI 0.09-0.91, p<0.05). Similarly, males were less likely than females to have depressive symptoms (COR: 0.20, 95\% CI 0.09-0.48; AOR: $0.15,95 \%$ CI $0.05-0.42, \mathrm{p}<0.05)$. Being in the first and second years of residency significantly increases the 


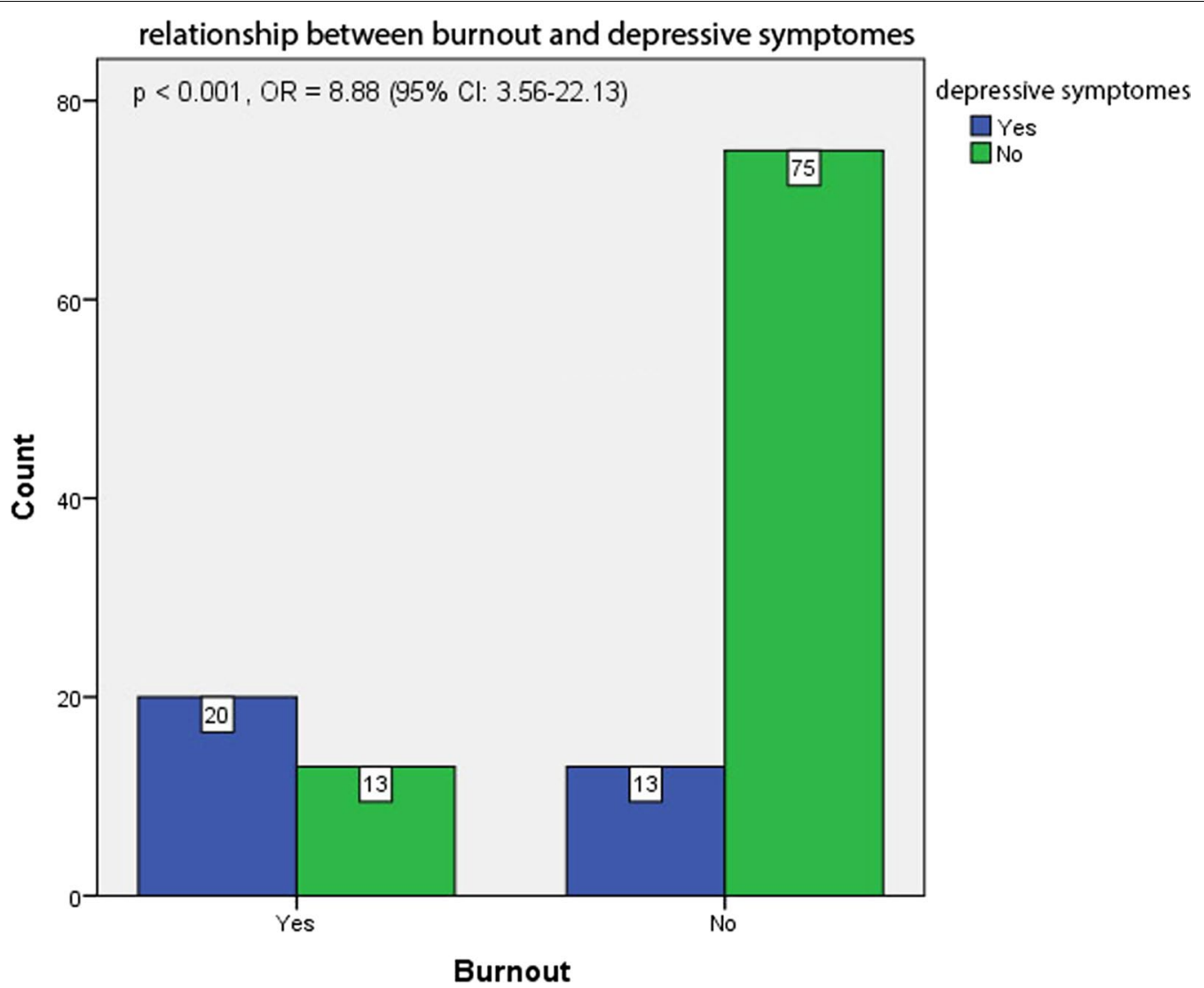

Fig. 1 Relationship between burnout and depressive symptoms among the study population (Chi square $=25.42, p<0.001, C O R: 8.88,95 \% \mathrm{Cl}$ 3.56-22.13)

Table 3 Relationship between burnout subscales and depressive symptoms $(n=121)$

\begin{tabular}{|c|c|c|c|c|c|c|c|c|}
\hline \multirow[t]{2}{*}{ Subscales } & \multirow[t]{2}{*}{ Values } & \multicolumn{2}{|c|}{ Depressive symptoms } & \multirow[t]{2}{*}{ Total } & \multicolumn{2}{|c|}{ Crude OR } & \multicolumn{2}{|c|}{ Adjusted OR } \\
\hline & & Yes $(n=33)$ & No $(n=88)$ & & OR & $95 \% \mathrm{Cl}$ & OR & $95 \% \mathrm{Cl}$ \\
\hline \multirow[t]{2}{*}{ High emotional exhaustion } & Yes & $20(62.5 \%)$ & $12(37.5 \%)$ & 32 & $9.74^{*}$ & $3.86-24.61$ & $5.60^{*}$ & $1.94-16.12$ \\
\hline & No & $13(14.6 \%)$ & $76(85.4 \%)$ & 89 & 1 & & & \\
\hline \multirow[t]{2}{*}{ High depersonalization } & Yes & $10(76.9 \%)$ & $3(23.1 \%)$ & 13 & $12.32^{*}$ & $3.13-48.48$ & 3.33 & $0.67-16.47$ \\
\hline & No & $23(21.3 \%)$ & 85 (78.7\%) & 108 & 1 & & & \\
\hline \multirow[t]{2}{*}{ Low personal accomplishment } & Yes & $15(51.7 \%)$ & $14(48.3 \%)$ & 29 & $4.40^{*}$ & $1.81-10.75$ & $2.84^{*}$ & $1.02-7.94$ \\
\hline & No & $18(19.6 \%)$ & $74(80.4 \%)$ & 92 & 1 & & & \\
\hline
\end{tabular}

Crude OR crude odds ratio

* Significant at $\mathrm{p}<0.05$

chances of having depressive symptoms as the respondents' data shows (COR: 2.20, 95\% CI 0.96-5.02; AOR: 3.29, 95\% CI 1.16-9.34, p <0.05). Residents who have received any mental health help in the last 2 years were significantly more likely than those who have not to have depressive symptoms (COR: 5.28 , 95\% CI
2.11-13.20; AOR: 3.97, 95\% CI 1.38-11.38, p <0.05). Even though not statistically significant, respondents who were alone, because they were single or divorced were more likely than their married counterparts to have depressive symptoms (COR: 1.34, 95\% CI 0.593.03; AOR: $1.10,95 \%$ CI 0.36-3.37). 
Table 4 Relationship between burnout and socio-demographic/educational factors $(n=121)$

\begin{tabular}{|c|c|c|c|c|c|c|c|c|}
\hline \multirow[t]{2}{*}{ Variables } & \multirow[t]{2}{*}{ Values } & \multicolumn{2}{|c|}{ Burnout $(n, \%)$} & \multirow[t]{2}{*}{ Total } & \multicolumn{2}{|c|}{ Crude OR } & \multicolumn{2}{|c|}{ Adjusted OR } \\
\hline & & Yes $(n=33)$ & No $(n=88)$ & & OR & $95 \% \mathrm{Cl}$ & OR & $95 \% \mathrm{Cl}$ \\
\hline \multirow[t]{2}{*}{ Age } & 24-28 years & $22(26.8 \%)$ & $60(73.2 \%)$ & 82 & 0.93 & $0.40-2.19$ & 0.82 & $0.29-2.30$ \\
\hline & $\geq 29$ years & 11 (28.2\%) & $28(71.8 \%)$ & 39 & 1 & & & \\
\hline \multirow[t]{2}{*}{ Sex } & Male & 15 (21.4\%) & $55(78.6 \%)$ & 70 & 0.50 & $0.22-1.12$ & 0.61 & $0.25-1.53$ \\
\hline & Female & $18(35.3 \%)$ & $33(64.7 \%)$ & 51 & 1 & & & \\
\hline \multirow[t]{2}{*}{ Marital status } & Single/divorced & 20 (29.9\%) & 47 (70.1\%) & 67 & 1.34 & $0.59-3.03$ & 0.97 & $0.34-2.77$ \\
\hline & Married & $13(24.1 \%)$ & 41 (75.9\%) & 54 & 1 & & & \\
\hline \multirow[t]{2}{*}{ Raising children } & Yes & $5(17.2 \%)$ & 24 (82.8\%) & 29 & 0.48 & $0.17-1.38$ & 0.54 & $0.13-2.16$ \\
\hline & No & $28(30.4 \%)$ & $64(69.6 \%)$ & 92 & 1 & & & \\
\hline \multirow[t]{2}{*}{ Current level } & $\mathrm{R} 1-\mathrm{R} 2$ & $19(31.7 \%)$ & 41 (68.3\%) & 60 & 1.56 & $0.69-3.49$ & 1.52 & $0.60-3.81$ \\
\hline & R3 - R4 & $14(23.0 \%)$ & 47 (77.0\%) & 61 & 1 & & & \\
\hline \multirow[t]{2}{*}{ Got mental help } & Yes & $16(59.3 \%)$ & 11 (40.7\%) & 27 & $6.59^{*}$ & $2.60-16.70$ & $5.80^{*}$ & 2.19-15.35 \\
\hline & No & $17(18.1 \%)$ & 77 (81.9\%) & 94 & 1 & & & \\
\hline
\end{tabular}

Crude $O R$ crude odds ratio

* Significant at $\mathrm{p}<0.05$

Table 5 Relationship between depressive symptoms and socio-demographic/educational factors $(n=121)$

\begin{tabular}{|c|c|c|c|c|c|c|c|c|}
\hline \multirow[t]{2}{*}{ Variables } & \multirow[t]{2}{*}{ Values } & \multicolumn{2}{|c|}{ Depressive symptoms (n, \%) } & \multirow[t]{2}{*}{ Total } & \multicolumn{2}{|c|}{ Crude OR } & \multicolumn{2}{|c|}{ Adjusted OR } \\
\hline & & Yes $(n=33)$ & No $(n=88)$ & & OR & $95 \% \mathrm{Cl}$ & OR & $95 \% \mathrm{Cl}$ \\
\hline \multirow[t]{2}{*}{ Age } & 24-28 years & $20(24.4 \%)$ & $62(75.6 \%)$ & 82 & 0.65 & $0.28-1.49$ & $0.29^{*}$ & $0.09-0.91$ \\
\hline & $\geq 29$ years & $13(33.3 \%)$ & $26(66.7 \%)$ & 39 & 1 & & & \\
\hline \multirow[t]{2}{*}{ Sex } & Male & $10(14.3 \%)$ & $60(85.7 \%)$ & 70 & $0.20^{*}$ & $0.09-0.48$ & $0.15^{*}$ & $0.05-0.42$ \\
\hline & Female & $23(45.1 \%)$ & $28(54.9 \%)$ & 51 & 1 & & & \\
\hline \multirow[t]{2}{*}{ Marital status } & Single/divorced & $20(29.9 \%)$ & $47(70.1 \%)$ & 67 & 1.34 & $0.59-3.03$ & 1.10 & $0.36-3.37$ \\
\hline & Married & $13(24.1 \%)$ & $41(75.9 \%)$ & 54 & 1 & & & \\
\hline \multirow[t]{2}{*}{ Raising children } & Yes & $5(17.2 \%)$ & $24(82.8 \%)$ & 29 & 0.48 & $0.17-1.38$ & 0.50 & $0.12-2.15$ \\
\hline & No & $28(30.4 \%)$ & $64(69.6 \%)$ & 92 & 1 & & & \\
\hline \multirow[t]{2}{*}{ Current level } & $\mathrm{R} 1-\mathrm{R} 2$ & $21(35.0 \%)$ & 39 (65.0\%) & 60 & 2.20 & $0.96-5.02$ & $3.29^{*}$ & $1.16-9.34$ \\
\hline & R3 - R4 & $12(19.7 \%)$ & 49 (80.3\%) & 61 & 1 & & & \\
\hline \multirow[t]{2}{*}{ Got mental help } & Yes & 15 (55.6\%) & $12(44.4 \%)$ & 27 & $5.28^{*}$ & $2.11-13.20$ & $3.97^{*}$ & $1.38-11.38$ \\
\hline & No & $18(19.1 \%)$ & 76 (80.9\%) & 94 & & & & \\
\hline
\end{tabular}

Crude $O R$ crude odds ratio

* Significant at $\mathrm{p}<0.05$

\section{Discussion}

This study aims to assess the prevalence of burnout, depressive symptoms, and their correlation during the COVID-19 pandemic among psychiatry residents in Saud Arabia. Our study revealed that about $27.3 \%$ of the participants were suffering from burnout. This finding seems to be lower than the results of the study by Jovanović and colleagues, who reported the prevalence of burnout among psychiatric trainees in 22 countries to be $36.7 \%$ [11]. However, our finding is within the range of burnout rates reported by residents from different medical specialties (13\% to $80 \%$ ) [22]. The lower prevalence in our study could be attributed to the reduction in all hospital activity and resident duties in the early days of the pandemic. However, psychiatry residents are among the entire health-care system that is thought to be affected during the pandemic. Multiple sources are thought to increase burnout among the study population during the pandemic. Some of these sources are the new policies and rules, stress among staff, and the fact that infected individuals could be encountered in the workplace at any time [23]. Factors not related directly to the pandemic could also contribute to burnout among the study population, such as dealing with suicidal and homicidal patients, difficulty separating one's personal life from professional life, and dealing with sensitive and 
emotional patients [24]. In addition, psychiatrists' personality traits may make them more vulnerable to burnout as they tend to internalize their stressful experiences [25].

Regarding depression, our result showed that $27.3 \%$ of the participants were suffering from depressive symptoms. This result is in line with the result of a rapid systematic review conducted by Ricci-Cabello and colleagues. They reported that the pool prevalence of depression among health care workers during a viral epidemic outbreak was 38\% [10]. Our study also aimed to analyze the complex associations between depressive symptoms and burnout among the study population. We found a significant relationship between burnout and depressive symptoms. It is still debatable whether burnout syndrome and depressive symptoms arise from the same situation, or are two different conditions [26]. There was a statistically significant positive correlation between all three burnout subscales (EE, DP, and PA) and depressive symptoms. This strong correlation highlights the importance of early recognition of burnout symptoms, where it is significantly predictive of depressive symptoms.

Burnout among psychiatry residents was associated with several sociodemographic factors that have an impact on whether the participants experienced burnout or not. In this study, the sociodemographic data, including age, sex, marital status, and raising children, had no statistically significant impact on the prevalence of burnout. Similar findings were reported in a systematic review by Chan MK et al. [14]. They concluded that the data regarding the age and gender of participants were inconsistent in the rates of burnout.

However, in this study, we found that being alone (single, divorced) and in junior years of training (residence years one and two) were associated with experiencing burnout more than counterparts. This finding is consistent with many studies conducted among psychiatry residents included in a systematic review by Chan [14]. For example, Kealy and colleagues [27] reported that burnout rates in program year (PGY)-2 and PGY-3 residents ranged from 27 to $31 \%$ compared with $16 \%$ to $18 \%$ in PGY-4 and PGY-5 residents. Moreover, a study conducted among medical residents during the H1N1 outbreak in Mexico reported that younger age was a risk factor for burnout [28]. In our study, increased reporting of burnout during the first 2 years of training can be attributed to many factors, which could be related to the pressure of fast skill attainment in assessing, diagnosing, and managing patients while experiencing the circumstances surrounding dealing with psychiatric patients with COVID-19 in emergency, inpatient, and outpatient units.
In addition, respondents currently raising children were less likely to have burnout, as was observed in previous studies [29]11. This finding is also in agreement with a study conducted among emergency department nurses during the Middle East respiratory syndrome coronavirus in Korea [30].

Relationships between sociodemographic factors and depressive symptoms were mostly consistent with the results of previous studies [15]. Similar to the result shown in our study, females were reported to have more depression than males among psychiatry residents and the general population [15, 31]. In addition, a recent study in China during the COVID-19 pandemic showed a similar result, of more females with depression than males among health care workers [32]. Moreover, residents in their first and second years of training had an increased chance of having depressive symptoms compared to other years, and this finding is consistent with findings from another study [33].

Respondents who had received mental health help in the preceding 2 years before the study were 6.59 times significantly more likely to experience burnout and depressive symptoms than those who had not. An explanation for this finding is that respondents who received mental health help, whether due to having a mental illness or facing difficulty with stressors, are at higher risk of developing burnout. This emphasizes the importance of intrinsic factors related to personality traits that make them prone to internalize their stressful experience as well as deficient in coping skills to deal with the current pandemic [34].

Much attention has been paid to the frontline health care workers, although that all health care providers are affected by COVID-19, especially those in training. As highlighted by the World Health Organization on May 14,2020 , there is a need to urgently increase investment in mental health services or risk a massive increase in mental health conditions in the coming months [35]. Under these circumstances, mental health workers will be under more pressure and could be more prone to burnout in these coming months. Hence, the need to construct a plan to reduce this risk is more important than ever by conducting future studies and developing preventative strategies and effective treatment programs to prevent burnout and promote wellness.

When researching burnout, it may be difficult to decide whether to report the results separately for each dimension of burnout or whether to combine the dimensions. While it is preferable to treat burnout as a multidimensional construct for theoretical purposes, it is often more convenient for researchers to treat burnout as a unidimensional variable.[36]. 
One limitation of our study design that it cannot determine the impact of a pandemic. Other limitations include that the focus of the research was limited to a subgroup population in one country; therefore, it is important to expand the scope of participants to compare it with different cases in different countries. Moreover, at the time of data collection, the pandemic was at its early stages in Saudi Arabia, which might not represent the current burnout and depressive symptoms. In addition, factors such as weekly working hours and the type of care provided by residents, being in contact with COVID-19 patients, personality traits, coping plans, and job attitude could be examined as other factors influencing burnout and depression. Finally, follow-up studies are needed to assess progression or even a potential rebound effect of psychological manifestations once the imminent threat of COVID-19 subsides.

\section{Conclusions}

In conclusion, during pandemics, the role of psychiatrists as a source of psychological support and reassurance to the public and frontline workers is indispensable and vital, and their mental wellbeing is critical to meet these needs. In this study, the prevalence of burnout and depressive symptoms during the COVID19 outbreak was assessed among psychiatry residents in Saudi Arabia. Burnout symptoms were found in $27.3 \%$, and another $27.3 \%$ reported having depression symptoms. In addition, $16.5 \%$ reported having both burnout and depressive symptoms, with a significant relationship between the two conditions. Participants who were in the first 2 years of training and had a history of receiving mental health in the past 2 years are at higher risk of developing burnout and depressive symptoms. During pandemics, as highlighted by the World Health Organization, there is a need to urgently increase investment in mental health. Hence, the need to construct a plan to reduce this risk of burnout and depression is more important than ever by conducting future studies and developing preventative strategies and effective treatment programs to prevent burnout and promote wellness.

\section{Abbreviations \\ COVID-19: Coronavirus disease of 2019; MBI-HSS: Maslach Burnout Inventory (Human Services Survey); PHQ-9: Patient's Health Questionnaire; EE: Emotional exhaustion; DP: Depersonalization; PA: Personal accomplishment; PGY: Program year.}

\section{Acknowledgements}

We would like to extend our thanks to all respondents and participants who helped to circulate this survey during the process of data collection. Researchers would like to thank the Deanship of Scientific Research, Qassim University for funding publication of this project

\section{Authors' contributions}

Conceptualization, AA, and MA; Data curation, HA; Formal analysis, AA; Investigation, AA, HAs, HAl, AN and MA; Methodology, AA, HAs, HAl, AN and MA; Project administration, AA; Supervision, AA; Validation, AA, and HAs; Visualization, AA; Writing — original draft, AA, HAs, HAl, AN and MA; Writing — review and editing, AA, HAs, HAl, AN and MA. All authors read and approved the final manuscript.

\section{Funding}

This research received no external funding.

\section{Availability of data and materials}

The datasets used and/or analyzed during the current study are available from the corresponding author on reasonable request.

\section{Declarations}

Ethics approval and consent to participate

The study was approved by the Institutional Review Board of Qassim University (No.19-10-02), and informed consent was obtained from all participants in the study.

\section{Consent for publication}

Not applicable.

\section{Competing interests}

The authors declare that they have no competing interests.

\section{Author details \\ ${ }^{1}$ Department of Medicine, Unaizah College of Medicine and Medical Sciences, Qassim University, Buraydah, Al Qassim, Saudi Arabia. ${ }^{2}$ Adult Mental Health Department At King Abdelaziz Medical City, Ministry of National Guard, Health Affairs-Riyadh, Riyadh, Saudi Arabia. ${ }^{3}$ Department of Psychiatry, College of Medicine, Qassim University, Buraydah, Saudi Arabia. ${ }^{4}$ Department of Urol- ogy, College of Medicine, Majmaah University, Al Majma'ah, Saudi Arabia.}

Received: 3 August 2020 Accepted: 15 March 2021

Published online: 06 April 2021

\section{References}

1. Panagioti M, Geraghty K, Johnson J, Zhou A, Panagopoulou E, ChewGraham C, et al. Association between physician burnout and patient safety, professionalism, and patient satisfaction. JAMA Intern Med. 2018;178(10):1317. https://jamanetwork.com/journals/jamainternalmed icine/fullarticle/2698144. Accessed 13 Jul 2020

2. Corona - Novel Coronavirus (COVID-19). https://www.moh.gov.sa/en/ HealthAwareness/EducationalContent/Corona/Pages/Corona.aspx. Accessed 11 Apr 2020

3. Custodian of the Two Holy Mosques issues curfew order to limit spread of Novel Coronavirus from seven in the evening until six in the morning for 21 days starting in the evening of Monday March 23 The official Saudi Press Agency. https://www.spa.gov.sa/viewfullstory.php?lang=en\& newsid=2050402. Accessed 11 Apr 2020

4. Kumar S. Burnout in psychiatrists. World Psychiatry. 2007;6(3):186-9.

5. Maslach C, Schaufeli WB, Leiter MP. Ob urnout. 2001;15:397-422.

6. Maslach C, Jackson SE, Leiter MP. The Maslach Burnout inventory manual. Maslach Burn Invent. 2016;1996:191-217.

7. Wurm W, Vogel K, Holl A, Ebner C, Bayer D, Mörkl S, et al. Depressionburnout overlap in physicians. PLOS ONE. 2016;11(3):1-15.

8. Schonfeld IS, Laurent E, Vandel P, Bianchi R. Burnout and depression in psychiatric residents. Can J Psychiatry. 2016;61(11):737-8.

9. Ahola K, Hakanen J, Perhoniemi R, Mutanen P. Relationship between burnout and depressive symptoms: a study using the person-centred approach. Burn Res. 2014;1(1):29-37.

10. Cabello IR, Echavez JFM, Serrano-Ripoll MJ, Fraile-Navarro D, de Roque MAF, Moreno GP, et al. Impact of viral epidemic outbreaks on mental health of health-care workers: a rapid systematic review. J Affect Disord. 2020;277:347-57 
11. Jovanović N, Podlesek A, Volpe U, Barrett E, Ferrari S, Rojnic Kuzman M, et al. Burnout syndrome among psychiatric trainees in 22 countries: Risk increased by long working hours, lack of supervision, and psychiatry not being first career choice. Eur Psychiatry. 2016;32:34-41.

12. Rössler W. Stress, burnout, and job dissatisfaction in mental health workers. Eur Arch Psychiatry Clin Neurosci. 2012;262:2.

13. Li L, Wan C, Ding R, Liu Y, Chen J, Wu Z, et al. Mental distress among Liberian medical staff working at the China Ebola Treatment Unit: a cross sectional study. Health Qual Life Outcomes. 2015;13(1):1-6.

14. Chan MK, Chew QH, Sim K. Burnout and associated factors in psychiatry residents: a systematic review. Int J Med Educ. 2019;10:149-60.

15. MesaRíos FJ, Del Carmen L, Muñoz M. Screening for psychopathology symptoms in Mexican psychiatry residents. Acad Psychiatry. 2011;35(6):370-2.

16. Shanafelt TD, Balch CM, Bechamps GJ, Russell T, Dyrbye L, Satele D, et al Burnout and career satisfaction among american surgeons. Ann Surg. 2009;250(3):463-70.

17. Alotaibi AK, Alsalim A, Alruwaili F, Almubarak A, Alhamzah A, Albahlal $A$, et al. Burnout during ophthalmology residency training: A national survey in Saudi Arabia. Saudi J Ophthalmol. 2019;33(2):130-4.

18. Maslach C, Jackson SE, Leiter MP. Maslach burnout inventory manual. Palo Alto, CA: Consulting Psychologists Press; 1996.

19. Kroenke K, Spitzer RL, Williams JBW. The PHQ-9: validity of a brief depression severity measure. J Gen Intern Med. 2001;16(9):606-13.

20. AlHadi AN, AlAteeq DA, Al-Sharif E, Bawazeer HM, Alanazi H, AlShomran AT, et al. An arabic translation, reliability, and validation of Patient Health Questionnaire in a Saudi sample. Ann Gen Psychiatry. 2017;16:32.

21. Inoue T, Tanaka T, Nakagawa S, Nakato Y, Kameyama R, Boku S, et al. Utility and limitations of PHQ-9 in a clinic specializing in psychiatric care. BMC Psychiatry. 2012;3:12.

22. Chan MK, Chew QH, Sim K. Burnout and associated factors in psychiatry residents: a systematic review. Int J Med Educ. 2019;10:149-60.

23. Wu Y, Wang J, Luo C, Hu S, Lin X, Anderson AE, et al. A comparison of burnout frequency among oncology physicians and nurses working on the front lines and usual wards during the COVID-19 epidemic in Wuhan. China J Pain Symptom Manage. 2020;60(1):e60-5.

24. Rathod S, Roy L, Ramsay M, Das M, Birtwistle J, Kingdon D. A survey of stress in psychiatrists working in the Wessex Region. Psychiatr Bull. 2000;24(4):133-6.

25. Kumar S, Hatcher S, Huggard P. Burnout in psychiatrists: an etiological model. Int J Psychiatry Med. 2005;35(4):405-16.
26. Huri M, Bağış N, Eren H, Umaroğlu M, Orhan K. Association between burnout and depressive symptoms among Turkish dentists. J Dent Sci. 2016:11(4):353-9.

27. Kealy D, Halli P, Ogrodniczuk JS, Hadjipavlou G. Burnout among Canadian psychiatry residents: a national survey. Can J Psychiatry. 2016;61(11):732-6.

28. Austria-Corrales F, Cruz-Valdés B, Herrera-Kiengelher L, García-Vázquez JC, Salas-Hernández J. Síndrome de burnout en médicos mexicanos en entrenamiento durante una contingencia sanitaria por virus de influenza A H1N1. Gac Med Mex. 2011;147(2):97-103.

29. Woodside JR, Miller MN, Floyd MR, McGowen KR, Pfortmiller DT. Observations on burnout in family medicine and psychiatry residents. Acad Psychiatry. 2008;32(1):13-9.

30. Kim JS, Choi JS. Factors influencing emergency nurses' burnout during an outbreak of middle east respiratory syndrome coronavirus in Korea. Asian Nurs Res (Korean Soc Nurs Sci). 2016;10(4):295-9.

31. Hasin DS, Sarvet AL, Meyers JL, Saha TD, Ruan WJ, Stohl M, et al. Epidemiology of adult DSM-5i major depressive disorder and its specifiers in the United States. JAMA Psychiatry. 2018;75(4):336-46.

32. Lai J, Ma S, Wang Y, Cai Z, Hu J, Wei N, et al. Factors associated with mental health outcomes among health care workers exposed to coronavirus disease 2019. JAMA Netw open. 2020;3(3):e203976.

33. Mata DA, Ramos MA, Bansal N, Khan R, Guille C, Di Angelantonio E, et al. Prevalence of depression and depressive symptoms among resident physicians a systematic review and meta-analysis. JAMA - J Am Med Assoc. 2015;314(22):2373-83.

34. Kumar S. Burnout and psychiatrists: what do we know and where to from here? Epidemiol Psychiatr Sci. 2011;20(4):295-301.

35. Substantial investment needed to avert mental health crisis. https:// www.who.int/news-room/detail/14-05-2020-substantial-investmentneeded-to-avert-mental-health-crisis. Accessed 17 May 2020

36. Brenninkmeijer $\bigvee$, VanYperen N. How to conduct research on burnout: Advantages and disadvantages of a unidimensional approach in burnout research. Occup Environ Med. 2003;60(SUPPL. 1):i16. www.occenvmed. com. Accessed 7 Nov 2020

\section{Publisher's Note}

Springer Nature remains neutral with regard to jurisdictional claims in published maps and institutional affiliations.
Ready to submit your research? Choose BMC and benefit from:

- fast, convenient online submission

- thorough peer review by experienced researchers in your field

- rapid publication on acceptance

- support for research data, including large and complex data types

- gold Open Access which fosters wider collaboration and increased citations

- maximum visibility for your research: over $100 \mathrm{M}$ website views per year

At BMC, research is always in progress.

Learn more biomedcentral.com/submissions 